\title{
Testing the law of one-price in the US gasoline market: a long memory approach
}

\author{
Marco R. Barassi \\ Gianluigi De Pascale \\ Raffaele Lagravinese
}

SERIES Working PAPERS N. 03/2021

SERIES sono pubblicati a cura del Dipartimento di Scienze economiche e metodi matematici dell'Università degli Studi di Bari "Aldo Moro". I lavori riflettono esclusivamente le opinioni degli autori e non impegnano la responsabilità del Dipartimento. SERIES vogliono promuovere la circolazione di studi ancora preliminari e incompleti, per suscitare commenti critici e suggerimenti. Si richiede di tener conto della natura provvisoria dei lavori per eventuali citazioni o per ogni altro uso.
SERIES are published under the auspices of the Department of Economics of the University of Bari. Any opinions expressed here are those of the authors and not those of the Department. Often SERIES divulge preliminary or incomplete work, circulated to favor discussion and comment. Citation and use of these paper should consider their provisional character. 


\title{
Testing the law of one-price in the US gasoline market: a long memory approach
}

\author{
Marco R. Barassi \\ Department of Economics \\ Gianluigi De Pascale \\ University of Birmingham \\ Department of Economics \\ University of Foggia \\ Raffaele Lagravinese \\ Department of Economics and Finance \\ University of Bari "A.Moro"
}

\begin{abstract}
This paper aims to shed new light on "law of one-price" in the United States' gasoline market over the period June-2003-December-2019. Specifically, we test for convergence of the retail prices of gasoline in different US PADDs, states and cities using the Local Whittle estimator (LW) and its variants (Robinson 1995, Shimotsu and Phillips 2005). Mean/trend reversion of the relative price of each unit will imply convergence toward the average price in the US thereby offering support for the law of one-price. LW estimators allow us to consider the case where relative gasoline price are fractionally integrated process and may display long memory implying a slow process of convergence. The results obtained generally offer support for the law of one-price albeit with significant differences in the rate of convergence between PADDs, States and Cities.
\end{abstract}

Keywords: Gasoline price, Convergence, Fractional integration, Whittle estimator.

JEL Classification: Q4, Q41, C01, C22 


\section{Introduction}

This paper investigates the Law of one Price (LOP hereafter) in United States gasoline market over the period June-2003-December-2019 using a long memory approach which relies on the Local Whittle estimator (LW) and its variants (Robinson 1995, Shimotsu and Phillips 2005). The LOP states that in the absence of arbitrage or trade frictions (such as transport costs and tariffs), and under conditions of perfect competition and price flexibility (where no individual sellers or buyers have the power to manipulate prices and prices can freely adjust), identical goods sold in different locations must sell for the same price when prices are expressed in a common currency (Persson, 2008).

The reason to study the LOP on gasoline market lies in the fact that fuel is a strategic productive factor for the economy of a country in general and, particularly, for the lives of people and businesses. The retail gasoline price substantially affects the costs of production and, at the same time, has a significant impact on the mobility of vehicles and people (Bösch et al., 2018). For the gasoline market, the LOP would be seen to hold if the difference in prices at-the-pump in different locations either is, or converges to zero.

In this paper we focus on the convergence between the retail prices of gasoline within three sets of US units: Petroleum Administration Defense Districts (PADDs), States and Cities. Studying the convergence of gasoline prices in the US is particularly important, both for evaluating the deregulation process that has involved this market since the 1980s, and because of the significant economic differences that has persisted in recent years between and within the US states and cities. The US states represent a particularly relevant case study thanks to a far greater capital and people mobility compared to that in European states. Indeed, US states share widely interdependent production processes and federal and state public policies that can certainly have effects between neighboring states. Yet, despite a much more pronounced integration process than in Europe, several studies in recent years have shown that there are still significant price differences between US states. It has been seen that these differences are partly generated in the various intermediate steps between the price of crude oil and the price at-the-pump (Blair et al., 2017; Borenstein et al., 1997), and accentuated as a result of structural breaks (Bagnai and Ospina, 2018). With regard to the gasoline market, within individual countries/regions or in any case in the presence of homogeneous territories that share the same market, it would be desirable to have the same price at the pump in order to avoid tax dumping or alterations in the price of goods due to asymmetries in the price of production factors. For example, Cárdenas et al. (2017) analyzed the diesel convergence process between gas stations in France, finding a significant convergence between the various most homogeneous and close geographic areas. Suvankulov et al. (2012) analyzed the integration process in Canadian provinces between 2000 and 2010 by observing a substantial convergence of prices on average but with six cities in the province of Nova Scotia which had a 
divergent pattern compared to the rest of the country. Balaguer and Ripollés (2018) observe a significant divergence in the price of gasoline in the Spanish provinces suggesting a lack of market integration at regional level. The different level of prices can be attributed to transportation costs, taxation, and other explicit barriers. Furthermore, the price convergence can shift an energy tax burden onto the producers which leads to a competitive disadvantage for firms in high-tax regions (Holmes et al. (2013); Suvankulov et al. (2012)). To date, most studies on the US gas price convergence process have focused on integrating the 7 PADDs into which the 50 American states are divided. In particular, Paul et al. (2001) analyze the integration of gasoline price from January 1983 to December of 1998 in the PADDS and finds a high degree of market integration in the gasoline markets as evidenced by the Engle and Granger and Johansen cointegration tests. Ye et al. (2005) investigate the pass-through mechanism from wholesale gasoline spot prices to retail gasoline prices on a regional basis. Their results underline the presence of Asymmetric price transmission (called the "rockets and feathers phenomenon" ${ }^{3}$ ) in all regions with price increases being passed along faster than price decreases. Two other works reach the same results, looking respectively at the individual Deltas states (2008) and at individual American cities (Arano and Velikova, 2009; Chesnes, 2016). Holmes et al. (2013) employ a pair-wise approach to examine regional integration using State date in the US gasoline market. Their findings show that a price convergence to the long-run equilibrium depends on distance and station homogeneity between states. More recently, Blair et al. (2017) used an error-correction model in a seemingly unrelated regression framework to examine the differences between PADDs. Their finding suggest that regional differences exist both in the short run and long run adjustment processes.

This paper attempts to enrich this literature on the LOP by introducing two significant novelties. The first is methodological in nature since as far as we are aware, it is the first time that a long memory approach is used in this strand of literature. The reason for our choice of methodology stems from the fact that the studies conducted so far have shown how different methodologies lead to conflicting results with respect to the convergence process between prices in the different geographical areas. We believe that the reason for these contrasting results is mostly due to the fact that previous studies have always confined the analysis within the I(1)-I(0) world, where I(1) non-stationary relative prices would indicate lack of convergence while stationary $\mathrm{I}(0)$ relative prices indicate convergence and support for the LOP. The second novelty lies instead in the geographical areas analyzed. Indeed, so far, given the availability of the data, the main studies on the subject have concerned the PADDs (e.g. Holmes et al. (2013); Paul et al. (2001)) or the States (Blair et al., 2017). However, in addition to offering an updated historical series for the individual PADDs, the Energy

\footnotetext{
${ }^{3}$ rockets and feathers" refers to pricing phenomenon occurring when downstream prices react in a different manner to upstream price changes, depending on the characteristics of upstream prices or changes in those prices.
} 
Information Administration (EIA) offers monthly data for 9 states and 10 cities for period from 2003 to 2019.

In brief, we exploit the entire information base made available by the EIA to test the convergence / divergence process through the Local Whittle (LW) estimator (Robinson 1995) of the fractional integration parameter and its variations (Exact Local Whittle (ELW) and Feasible Exact Local Whittle (FELW) in order to test the hypothesis that relative gasoline prices contain a unit root (non convergence) against the alternative that they are long memory processes implying slow convergence. Our analysis shows significant differences in the results as compared to those obtained using Augmented Dickey Fuller (ADF) and the Kwaitowsky, Phillips, Schmidt and Shin (KPSS) type of tests. In particular, our findings suggest that all series analysed are convergent but with very different speeds. In detail, a slow convergence (long memory process) is observed for PADD3 (Gulf Coast), PADD5 (West Coast) and then confirmed at the level of States (California, Texas and Washington) and at the level of Cities (Los Angeles, San Francisco and Huston). Among the cities, two of four empirical model employed find a slow convergence process is also in the cities of New York, Cleveland and Miami.

The remainder of the paper is structured as follows: Section 2 describes the data for the individual PADDs / States / Cities. Section 3 describes the estimation and testing methodology, Section 4 reports the results, and Section 5 offers some conclusions.

\section{Data}

We use the monthly data on the Retail Gasoline Prices (Dollars per Gallon) from the Energy Information Administration (EIA) of the US government at www.eia.gov. The time series are provided at PADD level which aggregates the 50 states from June 1993 until December 2019. Originally, the 50 American states were divided into five PADDs (East Coast, Midwest, Gulf Coast, Rocky Mountain, and West Coast) to capture the five major regions and later the East Coast PADD was further divided into 3: 1A (New England), PADD 1B (New York to Maryland), and PADD 1C (Virginia to Florida). This outline derives from the II world war, when U.S. government equipped a chain to supply the war machine with fuel, and has been kept beyond the conflict until today as a geographical framework for data collection being managed by EIA.

The EIA also collects and provides data series for 9 states (Florida, Massachusetts, Minnesota, New York, Ohio, Texas, Washington, Colorado and California) and 10 cities (Boston, Chicago, Denver, Houston, Los Angeles, Miami, New York City, San Francisco, Cleveland and Seattle). Unlike previous studies (e.g. (Blair et al., 2017; Paul et al., 2001), it was therefore decided not to analyze only the PADDs but to offer a more detailed analysis at the level of single states and specific cities in order to observe if there was heterogeneity between geographical areas. The time series are available for PADDs, States and Cities from June 2003 until December 2019, so our 
analysis is carried out in this temporal spam. Figure 1 shows in detail the partition in PADDs and identifies the states and cities object of our analysis.

\section{(please insert Figure 1 about here)}

Figures 2, 3 and 4, on the other hand, show the trend of the retail gasoline price for the PADDs, States and Cities analyzed (in logarithms).

The PADD level analysis offers a general overview of the gasoline price evolution that does not take into consideration the price dynamics reflecting the specific features of states and cities. Therefore, to deal with these probable differences due to the level of aggregation which can be caused by heterogeneity within each unit, we also look at convergence of gasoline prices using data at State and City levels. In this respect, Figure 3 shows the price evolution of the 9 states for which EIA collects data, while Figure 4 reports the prices of the 10 cities available. For the purpose of this study, such a comparison between results for different sets of units, aims at testing the robustness of the results in that, if there is homogeneity of the price trends at all levels of aggregation, our analysis should deliver consistent results. On the other hand, heterogeneity within the different levels of data aggregation (i.e. the case where Houston is very different from the rest of Texas which is very different from the rest of the states in PADD3) is likely to returns different and even contrasting results. This will all be confirmed or otherwise by the long memory approach used here, whose results will shed some light not only on whether the law of one-price (convergence between gasoline prices) holds in the US, but will also allow us to understand the degree of heterogeneity/homogeneity between the units.

At first glance, Figure 2 seems to reveal similar evolution in the prices across the 7 PADDs for the whole time-span. Although the increasing trends, the gasoline prices are affected by a significant volatility between 2003 and 2008. In 2008, indeed, the world economic and financial crisis caused a structural break so that PADD' gasoline prices collapsed. From then to 2011, prices turned to rise until 2011 when the price evolution became stable for almost three years. In 2014, prices dramatically collapsed again, then turned to slowly increase. Figure 3 reports the gasoline price of the 9 US states collected by EIA. From this perspective, the graphical illustration confirm an homogeneous trend for 8 out of 9 states. These trends, in turn, reflect those of the PADDs they belong to. By contrast, in California the situation appears changing since 2015: the gasoline price evolution takes different pathway compared to the PADD5 (West Coast). The heterogeneity emerges due to data disaggregation. Figure 4 breaks further down the data by considering gasoline price at the 10 city level, as data are provided by EIA. In this case, 4 out of 10 cities lead to heterogeneous pathways compared to the PADDs level. This happens for Los Angeles, San Francisco and Seattle belonging to PADD5, and, with lower differences for Miami, included in PADD1C (Lower Atlantic). The evidence raised by city disaggregation confirms the signal concerning the West Coast conveyed by Figure 3. Importantly, the two cities located in California register a greater gasoline price increase in the last 5 years than 
what happens at PADD level, that is the result obtained with the country' level disaggregation. By contrast, Seattle shows a different price evolution, even though no differences were found out between PADD and state level (Washington).

Instead, Miami' prices registered a spike in 2017, before immediately declining and keep on following up this gait. The emerging trend in Miami, is different from the PADD1C and the Florida ones.

$$
\begin{aligned}
& \text { (please insert Figure } 2 \text { about here) } \\
& \text { (please insert Figure } 3 \text { about here) } \\
& \text { (please insert Figure } 4 \text { about here) }
\end{aligned}
$$

This first attempt of interpreting the U.S. gasoline price time series shall be compared to the analytic computation presented in the section 4 in order to realize if the series follow a reasonable (stationary) or a random walk path.

\section{Methodology}

The methodology employed is in line with (Barassi et al., 2011; Strazicich and List, 2003) previously adopted for $C O^{2}$ Emissions. In detail we carried out unit root, stationary and fractional integration tests on the basis that, if retail gasoline prices between a set of geographical areas (in our case we consider three different areas: PADDs, States, Cities) are converging (in a stochastic sense) then the log of the ratio of gasoline prices in the geographic are $g$ and the average of gasoline prices of the set of all geographic area $\left(R P_{g t}\right)$ should be a stationary or at least a mean (trend) reverting process. First of all we model the natural logarithm of a geographic area's gasoline prices $\left(R P_{g t}\right)$ as:

$$
R P_{g t}=R P_{g}^{*}+u_{g t}
$$

where $R P_{g}^{*}$ is a time invariant equilibrium differential,

$$
R P_{g}^{*}=\frac{G R P_{g}}{N^{-1} \sum_{g=1}^{N} G R P_{g}}
$$

$G R P_{g}$ is the gasoline price of a specific area $g$ and $u_{g t}$ is a time and area specific deviation from that differential which can be written as:

$$
u_{g t}=c_{g 0}+\epsilon_{g t}
$$

where $c_{g 0}$ is the initial deviation from the equilibrium differential and $\epsilon_{j t}$ are the $g^{\text {th }}$ geographic area each with mean zero and finite variance $\sigma_{j}^{2}$. Combining equations (2) and (4) we get:

$$
R P_{g t}=R P_{g}^{*}+c_{j 0}+\epsilon_{g t}
$$


Testing for non-convergence is then done by testing whether the relative gasoline prices in geographic area $g, y_{g t}=\left(R P_{g t}-R P_{g}^{*}\right)$ contain a unit root (or are indeed trend stationary or mean/trend reverting). In conducting the test, equation (5) is expanded to include a linear time trend (which may be area specific) such that after a re-ordering of terms, equation (5) can be re-written as:

$$
\left(R P_{g t}-R P_{g}^{*}\right)=c_{g 0}+\gamma_{g} t+\epsilon_{g t}
$$

The term on the left hand side of equation (5) is then tested for a unit root (trend stationarity) against the alternative of trend stationarity/mean reversion and long memory (unit root). If a unit root is rejected, for a given initial deviation from equilibrium $c_{g 0}$, stationarity/mean reversion (and long memory) of relative emissions can be taken as evidence of convergence of gasoline prices.

It is well known that standard unit root tests may provide incorrect results in the presence of structural breaks in the deterministic terms. Also, the tests used may have low power near the alternative, and moreover, they cannot provide information about the level of persistence of the series. In our analysis we consider the possibility that relative gasoline prices are actually mean/trend reverting long memory processes and that is the reason why standard unit roots or stationarity tests may fail to offer consistent findings with regard to their order of integration (see appendix for a short introduction on long memory). Fractional integration $\mathrm{I}(\mathrm{d})$ with $0<d<1$ of relative gasoline prices implies their high persistence (even covariance non-stationarity) but mean/trend reversion in the long run. This translates into the occurrence of perhaps slow convergence of a gasoline price relative to the national average price in the long run.

The use of fractional integration may also be motivated by the presence of occasional breaks in the price series which otherwise would be only weakly autocorrelated. This can be appealing in the case of gasoline prices because cities o country regulations, new technologies or catastrophic events (e.g. storms, earthquakes, epidemics), although infrequent, may still cause shifts in the deterministics of a specific geographical area's gasoline price series. Moreover, Granger and Hyung (2004) show that fractional integration and infrequent breaks may be virtually impossible to distinguish from each other and adopting fractional integration modelling strategies produce good forecasts.

\section{Results}

The results of our analysis are presented as follows. First, we test the relative gasoline prices of the various units for the null of a unit root/stationarity by means of ADF and KPSS. Then, we consider the possiblity that relative gasoline prices may be long memory processes and using the Local Whittle (LW), Exact Local Whittle (ELW), Feasible Exact Local Whittle estimators (FELW) and Feasible Exact Local Whittle 
estimators with de-trending (FELW dt) we test for the order of integration $d=1$ versus a fractional alternative, as discussed above. Our analysis is conducted for different geographical level (PADDs, States, Cities) to take into account any potential differences due to levels of data aggregation.

Table 1 provides the results of ADF unit root test and KPSS stationary test by including the trend and the constant in the auxiliary regressions. The ADF test is carried out under the null hypothesis that the series contains a unit root, which means that if the null hypothesis is not rejected, the series follows a random walk process $(\hat{d}=1)$ and as such it is not converging toward the cross-unit mean.

For the ADF test the issue of the choice of the optimal lag was addressed by means of the Modified Akaike's Information Criterion (MAIC). Table 1 shows that ADF tests cannot reject the null for all series (except for Denver), implying that the series are not converging. The KPSS test mostly confirms the results of ADF tests. However, it provides contrasting evidence in some cases as for example it cannot reject the null of stationary for one PADD (PADD1B), two States (Colorado and Massachussetts) and three cities (Boston, Denver and Miami) thus providing some evidence of convergence.

\section{(please insert Table 1 about here)}

Tables 2, 3 and 4 display the results of the LW-based tests versus the alternative of Long Memory for PADD, States and Cities, respectively. These findings report the estimated order of integration $(\hat{d})$ as well as the test statistic for the null that $d=1$ obtained by considering different bandwidths between 0.575 and 0.65 following the approach suggested by Shimotsu and Phillips $(2006)^{1}$. This statement applies to all the four methods used to test for long memory (LW, ELW, FELW, FELW dt).

In interpreting long memory tests it is worth bearing in mind the following implications of the different values of the estimated order of integration $d$ for the relative price series:

- A series with order of integration $I\left(0 \leq d<\frac{1}{2}\right)$ is mean/trend reverting and covariance stationary and therefore convergent (albeit slowly if $d>0$ );

- A series with order of integration $I\left(\frac{1}{2} \leq d<1\right)$ is still mean/trend reverting but not covariance stationary. The implication of this is that although the series still converges, it does that very slowly.

In reading the Tables, it is also recommended to pay particular attention to the values returned by FELW dt when the series contains a trend as it is more precise.

\footnotetext{
${ }^{1}$ The test statistic is then compared to the relevant quantiles reported in table A1 in Appendix. It is worth noticing that as suggested by Shimotsu and Phillips (2006) using a bandwidth between $[0.6,0.65]$ provides a distribution of the test statistic under the null hypothesis $H_{0}: \hat{d}=1$ where the 0.5 quantile (median) is closer to the mean value which is closer to 0 as $\alpha \rightarrow 6.5$. (Barassi et al., 2011; Dubois et al., 2004)
} 
In the table 2, the fractional integration tests show strong evidence of convergence for all PADDs, and for 4 of them (PADD1A, PADD1B, PADD2, PADD4) with an order of integration of relative gasoline price almost always less the 0.5 , and for PADD1C PADD3 and PADD5 with fractional integration order between 0.5 - 0.7. In detail, for the PADD1A (New England) there is evidence that the fractional integration order goes from 0.2305 through 0.4327 (in this case, the de-trending process is not necessary to be considered). For PADD1B (Central Atlantic), results suggest that the integration order revolves around 0 . This implies that the series is pretty much $I(0)$ stationary and takes a convergent pathway. For PADD1C (Lower Atlantic), the fractional integration order of FELW dt lies between 0.4365 and 0.6291, and for this range of values, the trend matters. There is, therefore, some good evidence of a long memory process that leads to a relatively slow convergence. For PADD2 (Mid West) the fractional integration order of FELW is stable around 0.3. It means that the long memory dynamism leads to a stationary gait resulting in convergence both when considering trend and no trend procedures. In PADD3 (Gulf Coast), the gasoline price series is always "non covariance-stationary" (both in case of trend and de-trend). The estimation of $\hat{d}$ provides values around 0.7 leading to the interpretation that it is still mean/trend reverting and characterised by a very slow convergence. For the PADD 4 (Rocky Mountain) the order of integration of FELW dt ranges from 0.04 and (that are not distinguishable from 0) to 0.10 implying a strong evidence of convergence. Finally, for PADD5 (West Coast), the fractional integration order is constant around 0.65 , as values resulted with de-trending procedure shall be considered. This result suggests that convergence occurs slowly and with a no stationarity in covariance.

\section{(please insert Table 2 about here)}

From Table 3 we observe strong evidence of convergence with stationarity in covariance for the states of Colorado, Florida, Massachussets, Minnesota, New York and Ohio, with an order of integration is always $<0.5$ regardless of the value of the bandwidth $\alpha$ and for all the four methods employed. Note that, however, the relative price of gasoline in Colorado is very likely to be an $I(0)$ stationary "short-memory" process. On the other hand, relative prices of California, Texas and Washington report an order of integration always above 0.5 indicating a possibly very slow convergence to "one-price" due to mean(trend) reversion but non-stationarity in covariance.

\section{(please insert Table 3 about here)}

Table 4 reports the results for the 10 American cities for which data are available. Again, in this case, the null of a unit root for relative prices of gasoline is rejected in almost all cases and very convincingly for some cities like Boston, Chicago and Denver where the estimates for $d$ are always $<0.5$ implying mean/trend reversion and covariance-stationarity albeit slow convergence. Furthermore, whilst there are no gasoline prices reporting an order of integration close to 0 , relative prices in New 
York City have order of integration $(\hat{d})$ ranging between 0.3113 and 0.5214 (in FELW model) and are mean reverting long memory processes but possibly not covariancestationary. The same situation occurs for the cities of Cleveland and Seattle where the estimated values of $d$ are found to be greater than 0.5 when using LW, ELW and FELW, but slighly below the covariance non-stationarity threshold when FELW de-trending is used (this ranges between 0.37 and 0.48 for Cleveland and between 0.44 and 0.45 for Seattle). The city of Miami, in contrast with the tendency emerged in its state (Florida), shows an integration order between 0.5944 and 0.6481 with FELW dt, implying a slower convergence process and non-stationarity in covariance. On the contrary, the cities of Los angeles and San Francisco present $(\hat{d})$ values in line with the state of California with a range between 0.62 and 0.65 . These results suggest, non-stationarity and very slow convergence. Houston has the highest $(\hat{d})$ values compared to all other cities (also in line with the state of Texas) suggesting a slower convergence process compared to the other cities (the $(\hat{d})$ values are higher in all estimated models ranging between 0.69 and 0.72 ).

\section{(please insert Table 4 about here)}

It is apparent that, overall, the estimated orders of (fractional) integration at PADD, State and City levels are in sharp contrast with those obtained by means of the ADF and KPSS type of tests. Our results clearly suggest that the law of one-price in US gasoline price market seems to hold, although the speed of convergence may be different between (and within) PADDs, states and cities. The change in speed of convergence area by area, may be linked to heterogeneous development of the private and public initiatives at State level, and mainly to the demand dynamics at City level. In this respect, as found by Holmes et al. (2013), the heterogeneous evolution of the price speed convergence is constrained by different taxation policies issued at state level, different capacity of the refineries as well as the number of retailers and the payload of the pipelines connecting the refineries with U.S. regions. Note that, this is in line with Blair et al. (2017) who argued that both in the short and long run there is heterogeneity in the speed of convergence that hinders the accomplishment of the law of one-price.

\section{Conclusions}

The retail gasoline may appear to be one of the sectors in which there is inevitable convergence in the US market, thanks to the homogeneity of the product, the deregulation policies of recent years and the full availability of price information. In this paper we have used an alternative approach to studying the convergence of gasoline prices between American PADDs, states and cities. Previous studies using different methodologies achieved mixed results on the process of convergence between US 
PADDs, States and Cities. Using the Local Whittle estimator of the fractional integration parameter and its variations (Exact Local Whittle and Feasible Exact Local Whittle) we have tested the hypothesis that relative retail gasoline prices contain a unit root (implying non-convergence) against the alternative that they are fractionally integrated long memory processes (implying convergence albeit a slow one). This has allowed us to consider a more flexible alternative than the usual stationarity with weak dependence implied by ADF type of tests. As it emerges from our analysis, the convergence process is not achievable at the same time or speed in different US geographical areas. This may be due to the existence of a variety of institutional actors, geographically dispersed markets due to transport constraints and different taxation. In detail our results suggest that while for 2 of our 7 PADDs, there is evidence to suggest that relative gasoline prices are not fractionally integrated processes and are instead $\mathrm{I}(0)$, evidence points at fractional integration of relative prices of gasoline for the remaining PADDs. These findings support the law of one-price in the long run and holds also among American states and cities. The results are fairly consistent for states and their cities like in the case of California, for Los Angeles and San Francisco and Texas with Houston. We found mean reversion also for others cities like New York City, Cleveland and Miami and their relative states (New York, Ohio, Colorado). However, for these states and cities the relative price series showed non stationarity in covariance and thus very slow convergence patterns.

We do not provide evidence of the numerical on time-price-slope to understand whether a slower convergence process is linked to a high price level so that decreasing like a feather toward the convergence point, but it is clear that the issue of being no co-variance stationary can generate spikes in increase such that turning to the convergence point of cross-sectional mean (the one-price) could happen much more slowly. Given the difference in our results, compared to the other studies, further analyses may be conducted on other markets (e.g. the electricity market) and in other geographical contexts (e.g. European countries, regions). 


\section{References}

Arano, K. and Velikova, M. (2009). Price convergence in natural gas markets: citygate and residential prices. The Energy Journal, 30(3).

Bagnai, A. and Ospina, C. A. M. (2018). Asymmetries, outliers and structural stability in the us gasoline market. Energy Economics, 69:250-260.

Balaguer, J. and Ripollés, J. (2018). The dynamics pattern of price dispersion in retail fuel markets. Energy Economics, 74:546-564.

Barassi, M. R., Cole, M. A., and Elliott, R. J. (2011). The stochastic convergence of co 2 emissions: a long memory approach. Environmental and Resource Economics, 49(3):367-385.

Blair, B. F., Campbell, R. C., and Mixon, P. A. (2017). Price pass-through in us gasoline markets. Energy Economics, 65:42-49.

Borenstein, S., Cameron, A. C., and Gilbert, R. (1997). Do gasoline prices respond asymmetrically to crude oil price changes? The Quarterly journal of economics, 112(1):305-339.

Bösch, P. M., Becker, F., Becker, H., and Axhausen, K. W. (2018). Cost-based analysis of autonomous mobility services. Transport Policy, 64:76-91.

Cárdenas, J., Gutiérrez, L. H., and Otero, J. (2017). Investigating diesel market integration in france: Evidence from micro data. Energy Economics, 63:314-321.

Chesnes, M. (2016). Asymmetric pass-through in us gasoline prices. The Energy Journal, 37(1).

Dubois, E., Lardic, S., and Mignon, V. (2004). The exact maximum likelihood-based test for fractional cointegration: critical values, power and size. Computational Economics, 24(3):239-255.

Granger, C. W. and Hyung, N. (2004). Occasional structural breaks and long memory with an application to the s\&p 500 absolute stock returns. Journal of empirical finance, 11(3):399-421.

Granger, C. W. and Joyeux, R. (1980). An introduction to long-memory time series models and fractional differencing. Journal of time series analysis, 1(1):15-29.

Holmes, M. J., Otero, J., and Panagiotidis, T. (2013). On the dynamics of gasoline market integration in the united states: Evidence from a pair-wise approach. Energy economics, 36:503-510.

HoskNG, J. (1981). Fractional differencing. Biometrika, 68:165-76. 
Paul, R. J., Miljkovic, D., and Ipe, V. (2001). Market integration in us gasoline markets. Applied Economics, 33(10):1335-1340.

Persson, K. (2008). Law of one price. EH. Net Encyclopedia, edited by Robert Whaples, 10.

Shimotsu, K. and Phillips, P. C. (2006). Local whittle estimation of fractional integration and some of its variants. Journal of Econometrics, 130(2):209-233.

Strazicich, M. C. and List, J. A. (2003). Are co 2 emission levels converging among industrial countries? Environmental and Resource Economics, 24(3):263-271.

Suvankulov, F., Lau, M. C. K., and Ogucu, F. (2012). Price regulation and relative price convergence: Evidence from the retail gasoline market in canada. Energy Policy, 40:325-334.

Ye, M., Zyren, J., Shore, J., and Burdette, M. (2005). Regional comparisons, spatial aggregation, and asymmetry of price pass-through in us gasoline markets. Atlantic Economic Journal, 33(2):179-192. 
Table 1 Unit Root tests for PADDs, Countries and Cities series - ADF vs. KPSS

\begin{tabular}{|c|c|c|c|c|c|}
\hline Series & $\begin{array}{c}\text { ADF } \\
(\text { Lag - MAIC) }\end{array}$ & $\mathrm{C} \& \mathrm{~T}$ & $\begin{array}{c}\text { KPSS } \\
\text { (Bandwith) }\end{array}$ & $\mathrm{C} \& \mathrm{~T}$ & Convergence? \\
\hline \multicolumn{6}{|l|}{ PADDs } \\
\hline PADD1A & $-1.141(10)$ & $\mathrm{c}$ & $0.272(8)$ & $\mathrm{c}+\mathrm{t}$ & $\mathrm{NO}$ \\
\hline PADD1B & $-2.042(11)$ & $\mathrm{c}$ & $0.076(3)$ & $\mathrm{c}+\mathrm{t}$ & YES(KPSS) \\
\hline PADD1C & $-1.357(10)$ & $\mathrm{c}+\mathrm{t}$ & $0.311(9)$ & $\mathrm{c}+\mathrm{t}$ & $\mathrm{NO}$ \\
\hline PADD2 & $-2.211(13)$ & $\mathrm{c}+\mathrm{t}$ & $0.372(7)$ & $c+t$ & $\mathrm{NO}$ \\
\hline PADD3 & $-2.348(10)$ & $\mathrm{c}+\mathrm{t}$ & $0.329(10)$ & $c+t$ & $\mathrm{NO}$ \\
\hline PADD4 & $-1.357(12)$ & $\mathrm{c}$ & $0.264(4)$ & $c+t$ & $\mathrm{NO}$ \\
\hline PADD5 & $-2.0530(6)$ & $\mathrm{c}+\mathrm{t}$ & $0.308(10)$ & $\mathrm{c}+\mathrm{t}$ & $\mathrm{NO}$ \\
\hline \multicolumn{6}{|l|}{ States } \\
\hline California & $-1.683(7)$ & $\mathrm{c}+\mathrm{t}$ & $0.320(10)$ & $\mathrm{c}+\mathrm{t}$ & $\mathrm{NO}$ \\
\hline Colorado & $-1.415(14)$ & $\mathrm{c}$ & $0.137(2)$ & $\mathrm{c}+\mathrm{t}$ & YES(KPSS) \\
\hline Florida & $-1.182(10)$ & $\mathrm{c}+\mathrm{t}$ & $0.197(7)$ & $c+t$ & $\mathrm{NO}$ \\
\hline Massachusetts & $-2.159(10)$ & $\mathrm{c}$ & $0.141(6)$ & $\mathrm{c}$ & YES(KPSS) \\
\hline Minnesota & $-1.321(10)$ & c & $0.377(8)$ & $c+t$ & $\mathrm{NO}$ \\
\hline New York & $-0.039(11)$ & $\mathrm{c}$ & $0.302(6)$ & $\mathrm{c}+\mathrm{t}$ & $\mathrm{NO}$ \\
\hline Ohio & $-2.438(14)$ & $\mathrm{c}+\mathrm{t}$ & $0.300(7)$ & $c+t$ & $\mathrm{NO}$ \\
\hline Texas & $-2.248(10)$ & $\mathrm{c}+\mathrm{t}$ & $0.324(10)$ & $c+t$ & $\mathrm{NO}$ \\
\hline Washington & $-1.732(12)$ & $\mathrm{c}+\mathrm{t}$ & $0.298(9)$ & $\mathrm{c}+\mathrm{t}$ & $\mathrm{NO}$ \\
\hline \multicolumn{6}{|l|}{ Cities } \\
\hline Boston & $-1.967(10)$ & $\mathrm{c}+\mathrm{t}$ & $0.146(8)$ & $\mathrm{c}+\mathrm{t}$ & YES(KPSS) \\
\hline Chicago & $-1.346(13)$ & $\mathrm{c}$ & $0.391(6)$ & $c+t$ & $\mathrm{NO}$ \\
\hline Cleveland & $-2.589(9)$ & $\mathrm{c}+\mathrm{t}$ & $0.359(9)$ & $c+t$ & NO \\
\hline Denver & $-5.853(0)$ & $c+t$ & $0.076(1)$ & $c+t$ & YES(both) \\
\hline Houston & $-2.256(8)$ & $\mathrm{c}+\mathrm{t}$ & $0.297(10)$ & $\mathrm{c}+\mathrm{t}$ & NO \\
\hline Los Angeles & $-2.240(7)$ & $\mathrm{c}+\mathrm{t}$ & $0.255(10)$ & $c+t$ & NO \\
\hline Miami & $-0.246(10)$ & $\mathrm{c}+\mathrm{t}$ & $0.159(9)$ & $c+t$ & YES(KPSS) \\
\hline New York City & $-1.877(10)$ & $\mathrm{c}+\mathrm{t}$ & $0.192(7)$ & $\mathrm{c}+\mathrm{t}$ & $\mathrm{NO}$ \\
\hline San Francisco & $-1.432(7)$ & $\mathrm{c}+\mathrm{t}$ & $0.352(10)$ & $\mathrm{c}+\mathrm{t}$ & NO \\
\hline Seattle & $-1.705(10)$ & $\mathrm{c}+\mathrm{t}$ & $0.302(9)$ & $\mathrm{c}+\mathrm{t}$ & $\mathrm{NO}$ \\
\hline
\end{tabular}

ADF critical values with const.+trend: -4.008 (1\%); -3.433 (5\%); -3.140 (10\%) ADF critical values with const.: $-3.465(1 \%) ;-2.876(5 \%) ;-2.574(10 \%)$ KPSS critical values with const.+trend: $0.216(1 \%) ; 0.146(5 \%) ; 0.119(10 \%)$ KPSS critical values with const.: $0.739(1 \%) ; 0.463(5 \%) ; 0.347(10 \%)$ 
Table 2 Long memory test for PADD' gasoline price time series

\begin{tabular}{|c|c|c|c|c|c|}
\hline & & LW & ELW & FELW & FELW dt \\
\hline \multicolumn{6}{|l|}{ PADD1A - 199 obs. } \\
\hline \multirow[t]{2}{*}{$\alpha=0.575$} & $\hat{d}$ & 0.2305 & 0.2751 & 0.2863 & 0.2763 \\
\hline & $H_{0}: \hat{d}=1$ & -3.4415 & -3.2420 & -3.1918 & -3.2364 \\
\hline \multirow[t]{2}{*}{$\alpha=0.6$} & $\hat{d}$ & 0.2902 & 0.3376 & 0.3397 & 0.3282 \\
\hline & $H_{0}: \hat{d}=1$ & -3.4040 & -3.1767 & -3.1666 & -3.2220 \\
\hline \multirow[t]{2}{*}{$\alpha=0.625$} & $\hat{d}$ & 0.3314 & 0.3770 & 0.3736 & 0.3616 \\
\hline & $H_{0}: \hat{d}=1$ & -3.4739 & -3.2371 & -3.2549 & -3.3172 \\
\hline \multirow[t]{2}{*}{$\alpha=0.65$} & $\hat{d}$ & 0.3914 & 0.4408 & 0.4327 & 0.4207 \\
\hline & $H_{0}: \hat{d}=1$ & -3.3888 & -3.1137 & -3.1587 & -3.2253 \\
\hline \multicolumn{6}{|l|}{ PADD1B - 199 obs. } \\
\hline \multirow[t]{2}{*}{$\alpha=0.575$} & $\hat{d}$ & -0.0056 & 0.0433 & 0.0009 & -0.1976 \\
\hline & $H_{0}: \hat{d}=1$ & -4.4971 & -4.2787 & -4.4683 & -4.4683 \\
\hline \multirow[t]{2}{*}{$\alpha=0.6$} & $\hat{d}$ & 0.0428 & 0.0714 & 0.0496 & -0.1238 \\
\hline & $H_{0}: \hat{d}=1$ & -4.5668 & -4.4534 & -4.5577 & -5.3894 \\
\hline \multirow[t]{2}{*}{$\alpha=0.625$} & $\hat{d}$ & 0.1030 & 0.1033 & 0.1006 & -0.0408 \\
\hline & $H_{0}: \hat{d}=1$ & -4.6608 & -4.6595 & -4.6736 & -5.4081 \\
\hline \multirow[t]{2}{*}{$\alpha=0.6$} & $\hat{d}$ & 0.1809 & 0.1556 & 0.1746 & 0.0728 \\
\hline & $H_{0}: \hat{d}=1$ & -4.5606 & -4.7013 & -4.5954 & -5.1624 \\
\hline \multicolumn{6}{|l|}{ PADD1C - 199 obs. } \\
\hline \multirow[t]{2}{*}{$\alpha=0.575$} & $\hat{d}$ & 0.4365 & 0.4506 & 0.4860 & 0.3929 \\
\hline & $H_{0}: \hat{d}=1$ & -2.5020 & -2.4571 & -2.2986 & -2.7152 \\
\hline \multirow[t]{2}{*}{$\alpha=0.6$} & $\hat{d}$ & 0.4648 & 0.4775 & 0.5155 & 0.4316 \\
\hline & $H_{0}: \hat{d}=1$ & -2.5666 & -2.5057 & -2.3235 & -2.7259 \\
\hline \multirow[t]{2}{*}{$\alpha=0.625$} & $\hat{d}$ & 0.5363 & 0.5492 & 0.5943 & 0.6298 \\
\hline & $H_{0}: \hat{d}=1$ & -2.4094 & -2.3423 & -2.1080 & -1.9239 \\
\hline \multirow[t]{2}{*}{$\alpha=0.65$} & $\hat{d}$ & 0.5504 & 0.5784 & 0.5992 & 0.6291 \\
\hline & $H_{0}: \hat{d}=1$ & -2.5031 & -2.3474 & -2.2318 & -2.0653 \\
\hline \multicolumn{6}{|l|}{ PADD2 - 199 obs. } \\
\hline \multirow[t]{2}{*}{$\alpha=0.575$} & $\hat{d}$ & 0.3130 & 0.2482 & 0.3201 & 0.2232 \\
\hline & $H_{0}: \hat{d}=1$ & -3.0724 & -3.3620 & -3.0408 & -3.4741 \\
\hline \multirow[t]{2}{*}{$\alpha=0.6$} & $\hat{d}$ & 0.2428 & 0.2190 & 0.2636 & 0.1738 \\
\hline & $H_{0}: \hat{d}=1$ & -3.6315 & -3.7455 & -3.5517 & -3.9623 \\
\hline \multirow[t]{2}{*}{$\alpha=0.625$} & $\hat{d}$ & 0.2867 & 0.2608 & 0.3086 & 0.2285 \\
\hline & $H_{0}: \hat{d}=1$ & -3.7062 & -3.8412 & -3.5926 & -4.0089 \\
\hline \multirow[t]{2}{*}{$\alpha=0.65$} & $\hat{d}$ & 0.2998 & 0.2801 & 0.3236 & 0.2518 \\
\hline & $H_{0}: \hat{d}=1$ & -3.8984 & -4.0082 & -3.7663 & -4.1658 \\
\hline
\end{tabular}


Table 2 continued

\begin{tabular}{llrrrr}
\hline & & LW & ELW & FELW & FELW dt \\
\hline PADD3 - 199 obs. & $\hat{d}$ & & & & \\
$\alpha=0.575$ & & 0.7568 & 0.6251 & 0.7577 & 0.7124 \\
& $H_{0}: \hat{d}=1$ & -1.0878 & -1.6764 & -1.0835 & -1.2862 \\
$\alpha=0.6$ & $\hat{d}$ & 0.7030 & 0.6311 & 0.7165 & 0.6832 \\
& $H_{0}: \hat{d}=1$ & -1.4245 & -1.7693 & -1.3597 & -1.5930 \\
$\alpha=0.625$ & $\hat{d}$ & 0.7589 & 0.6731 & 0.7524 & 0.7143 \\
& $H_{0}: \hat{d}=11$ & -1.2549 & -1.6986 & -1.2865 & -1.4844 \\
$\alpha=0.65$ & $\hat{d}$ & 0.7237 & 0.6881 & 0.7318 & 0.6970 \\
& $H_{0}: \hat{d}=1$ & -1.5381 & -1.7367 & -1.4930 & -1.6868 \\
\hline PADD4 - 199 obs. & $\hat{d}$ & & & & \\
$\alpha=0.575$ & $H_{0}: \hat{d}=1$ & -0.0066 & -0.0334 & -0.0645 & 0.0579 \\
& $\hat{d}$ & 0.0240 & -0.0009 & -0.0210 & -0.1940 \\
$\alpha=0.6$ & $H_{0}: \hat{d}=1$ & -4.6809 & -4.8000 & -4.8963 & -4.8890 \\
& $\hat{d}$ & 0.0778 & 0.0579 & 0.0493 & 0.0452 \\
$\alpha=0.625$ & $H_{0}: \hat{d}=1$ & -4.7931 & -4.8955 & -4.9398 & -4.9615 \\
& $\hat{d}$ & 0.1274 & 0.1156 & 0.1116 & 0.1042 \\
$\alpha=0.65$ & $H_{0}: \hat{d}=1$ & -4.8583 & -4.9243 & -4.9462 & -4.9877 \\
\hline PADD5 - 199 obs. & $\hat{d}$ & & & & \\
$\alpha=0.575$ & $\hat{d}$ & 0.7293 & 0.7609 & 0.7738 & 0.6637 \\
& $H_{0}: \hat{d}=1$ & -1.2108 & -1.0694 & -1.0118 & -1.5038 \\
$\alpha=0.6$ & $\hat{d}$ & 0.6826 & 0.7707 & 0.7243 & 0.6396 \\
& $H_{0}: \hat{d}=1$ & -1.5223 & -1.0995 & -1.3224 & -1.7284 \\
$\alpha=0.625$ & $\hat{d}$ & 0.7185 & 0.7354 & 0.7445 & 0.6576 \\
$\alpha=0.65$ & $H_{0}: \hat{d}=1$ & -1.4627 & -1.3747 & -1.3278 & -1.7791 \\
& $\hat{d}$ & 0.6836 & 0.6991 & 0.6828 & 0.6457 \\
& $H_{0}: \hat{d}=1$ & -1.7615 & -1.6756 & -1.7659 & -1.9728 \\
\hline
\end{tabular}


Table 3 Long memory test for State' gasoline price time series

\begin{tabular}{|c|c|c|c|c|c|}
\hline & & LW & ELW & FELW & FELW dt \\
\hline \multicolumn{6}{|l|}{ California - 199 obs. } \\
\hline \multirow[t]{2}{*}{$\alpha=0.575$} & $\hat{d}$ & 0.7516 & 0.7781 & 0.7768 & 0.6562 \\
\hline & $H_{0}: \hat{d}=1$ & -1.1110 & -0.9925 & -0.9983 & -1.5374 \\
\hline \multirow[t]{2}{*}{$\alpha=0.6$} & $\hat{d}$ & 0.6883 & 0.7503 & 0.7073 & 0.6309 \\
\hline & $H_{0}: \hat{d}=1$ & -1.4950 & -1.1976 & -1.4039 & -1.7701 \\
\hline \multirow[t]{2}{*}{$\alpha=0.625$} & $\hat{d}$ & 0.7433 & 0.7596 & 0.7572 & 0.6510 \\
\hline & $H_{0}: \hat{d}=1$ & -1.3338 & -1.2492 & -1.2616 & -1.8134 \\
\hline \multirow[t]{2}{*}{$\alpha=0.65$} & $\hat{d}$ & 0.7162 & 0.7459 & 0.7208 & 0.6408 \\
\hline & $H_{0}: \hat{d}=1$ & -1.5801 & -1.4149 & -1.5545 & -2.0000 \\
\hline \multicolumn{6}{|l|}{ Colorado - 199 obs. } \\
\hline \multirow[t]{2}{*}{$\alpha=0.575$} & $\hat{d}$ & 0.0069 & 0.0503 & -0.0103 & -0.1296 \\
\hline & $H_{0}: \hat{d}=1$ & -4.4414 & -4.2471 & -4.5180 & -5.0515 \\
\hline \multirow[t]{2}{*}{$\alpha=0.6$} & $\hat{d}$ & 0.0032 & 0.0494 & -0.0134 & -0.1217 \\
\hline & $H_{0}: \hat{d}=1$ & -4.7807 & -4.5588 & -4.8601 & -5.3797 \\
\hline \multirow[t]{2}{*}{$\alpha=0.625$} & $\hat{d}$ & 0.0496 & 0.0698 & 0.0329 & -0.0606 \\
\hline & $H_{0}: \hat{d}=1$ & -4.9384 & -4.8333 & -5.0251 & -5.5110 \\
\hline \multirow[t]{2}{*}{$\alpha=0.65$} & $\hat{d}$ & 0.0795 & 0.0838 & 0.0647 & -0.0158 \\
\hline & $H_{0}: \hat{d}=11$ & -5.1254 & -5.1013 & -5.2077 & -5.6558 \\
\hline \multicolumn{6}{|l|}{ Florida - 199 obs. } \\
\hline \multirow[t]{2}{*}{$\alpha=0.575$} & $\hat{d}$ & 0.3196 & 0.3620 & 0.3885 & 0.0651 \\
\hline & $H_{0}: \hat{d}=1$ & -3.0429 & -2.8533 & -2.7346 & -4.1808 \\
\hline \multirow[t]{2}{*}{$\alpha=0.6$} & $\hat{d}$ & 0.3610 & 0.3952 & 0.4224 & 0.1580 \\
\hline & $H_{0}: \hat{d}=1$ & -3.0645 & -2.9004 & -2.7700 & -4.0382 \\
\hline \multirow[t]{2}{*}{$\alpha=0.625$} & $\hat{d}$ & 0.4451 & 0.4613 & 0.4898 & 0.2960 \\
\hline & $H_{0}: \hat{d}=1$ & -2.8836 & -2.7993 & -2.6513 & -3.6583 \\
\hline \multirow[t]{2}{*}{$\alpha=0.65$} & $\hat{d}$ & 0.4986 & 0.5035 & 0.5271 & 0.3833 \\
\hline & $H_{0}: \hat{d}=1$ & -2.7919 & -2.7643 & -2.6330 & -3.4337 \\
\hline \multicolumn{6}{|l|}{ Massachussets - 199 obs. } \\
\hline \multirow[t]{2}{*}{$\alpha=0.575$} & $\hat{d}$ & 0.1092 & 0.1529 & 0.1404 & 0.1415 \\
\hline & $H_{0}: \hat{d}=1$ & -3.9837 & -3.7883 & -3.8443 & -3.8395 \\
\hline \multirow[t]{2}{*}{$\alpha=0.6$} & $\hat{d}$ & 0.1745 & 0.2059 & 0.2040 & 0.2029 \\
\hline & $H_{0}: \hat{d}=1$ & -3.9590 & -3.8084 & -3.8177 & -3.8228 \\
\hline \multirow[t]{2}{*}{$\alpha=0.625$} & $\hat{d}$ & 0.1977 & 0.2181 & 0.2209 & 0.2190 \\
\hline & $H_{0}: \hat{d}=1$ & -4.1687 & -4.0627 & -4.0486 & -4.0581 \\
\hline \multirow[t]{2}{*}{$\alpha=0.65$} & $\hat{d}$ & 0.2596 & 0.2822 & 0.2879 & 0.2846 \\
\hline & $H_{0}: \hat{d}=1$ & -4.1222 & -3.9966 & -3.9650 & -3.9829 \\
\hline
\end{tabular}


Table 3 continued

\begin{tabular}{|c|c|c|c|c|c|}
\hline & & LW & ELW & FELW & FELW dt \\
\hline \multicolumn{6}{|l|}{ Minnesota - 199 obs. } \\
\hline \multirow[t]{2}{*}{$\alpha=0.575$} & $\hat{d}$ & 0.3668 & 0.28299 & 0.3863 & 0.3369 \\
\hline & $H_{0}: \hat{d}=1$ & -2.8317 & -3.2069 & -2.7447 & -2.9656 \\
\hline \multirow[t]{2}{*}{$\alpha=0.6$} & $\hat{d}$ & 0.2832 & 0.2435 & 0.3142 & 0.2684 \\
\hline & $H_{0}: \hat{d}=1$ & -3.4379 & -3.6280 & -3.2890 & -3.5086 \\
\hline \multirow[t]{2}{*}{$\alpha=0.625$} & $\hat{d}$ & 0.3218 & 0.3027 & 0.3604 & 0.3198 \\
\hline & $H_{0}: \hat{d}=1$ & -3.5242 & -3.6234 & -3.3234 & -3.5345 \\
\hline \multirow[t]{2}{*}{$\alpha=0.65$} & $\hat{d}$ & 0.3691 & 0.3564 & 0.4057 & 0.3693 \\
\hline & $H_{0}: \hat{d}=1$ & -3.5127 & -3.5833 & -3.3091 & -3.5117 \\
\hline \multirow{3}{*}{$\begin{array}{l}\text { New York - } 199 \text { obs. } \\
\alpha=0.575\end{array}$} & & & & & \\
\hline & $\hat{d}$ & 0.1693 & -0.0410 & 0.2401 & 0.0750 \\
\hline & $H_{0}: \hat{d}=1$ & -3.7148 & -4.6553 & -3.3983 & -4.1366 \\
\hline \multirow[t]{2}{*}{$\alpha=0.6$} & $\hat{d}$ & 0.2180 & 0.2812 & 0.2709 & 0.1120 \\
\hline & $H_{0}: \hat{d}=1$ & -3.7505 & -3.4474 & -3.4967 & -4.2587 \\
\hline \multirow[t]{2}{*}{$\alpha=0.625$} & $\hat{d}$ & 0.2740 & 0.3867 & 0.3147 & 0.1656 \\
\hline & $H_{0}: \hat{d}=1$ & -3.7723 & -3.1870 & -3.5608 & -4.3357 \\
\hline \multirow[t]{2}{*}{$\alpha=0.65$} & $\hat{d}$ & 0.3459 & 0.4796 & 0.3785 & 0.2425 \\
\hline & $H_{0}: \hat{d}=1$ & -3.6418 & -2.8972 & -3.4602 & -4.2174 \\
\hline \multicolumn{6}{|l|}{ Ohio - 199 obs. } \\
\hline \multirow[t]{2}{*}{$\alpha=0.575$} & $\hat{d}$ & 0.3829 & 0.3223 & 0.3861 & 0.2742 \\
\hline & $H_{0}: \hat{d}=1$ & -2.7596 & -3.0306 & -2.7454 & -3.2459 \\
\hline \multirow[t]{2}{*}{$\alpha=0.6$} & $\hat{d}$ & 0.3362 & 0.2969 & 0.3448 & 0.2419 \\
\hline & $H_{0}: \hat{d}=1$ & -3.1833 & -3.3721 & -3.1421 & -3.6359 \\
\hline \multirow[t]{2}{*}{$\alpha=0.625$} & $\hat{d}$ & 0.3874 & 0.3385 & 0.3877 & 0.2998 \\
\hline & $H_{0}: \hat{d}=1$ & -3.1830 & -3.4372 & -3.1818 & -3.6383 \\
\hline \multirow[t]{2}{*}{$\alpha=0.65$} & $\hat{d}$ & 0.3232 & 0.2966 & 0.3345 & 0.2507 \\
\hline & $H_{0}: \hat{d}=1$ & -3.7685 & -3.9163 & -3.7055 & -4.1718 \\
\hline \multirow[t]{2}{*}{$\begin{array}{l}\text { Texas - } 199 \text { obs. } \\
\alpha=0.575\end{array}$} & 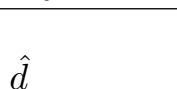 & 0.6407 & 0.5143 & 0.6810 & 0.6950 \\
\hline & $H_{0}: \hat{d}=1$ & -1.6068 & -2.1720 & -1.4267 & -1.3640 \\
\hline \multirow[t]{2}{*}{$\alpha=0.6$} & $\hat{d}$ & 0.6223 & 0.5553 & 0.6649 & 0.6820 \\
\hline & $H_{0}: \hat{d}=1$ & -1.8112 & -2.1327 & -1.6070 & -1.5250 \\
\hline \multirow[t]{2}{*}{$\alpha=0.625$} & $\hat{d}$ & 0.6893 & 0.6358 & 0.7205 & 0.7152 \\
\hline & $H_{0}: \hat{d}=1$ & -1.6144 & -1.8922 & -1.4525 & -1.4799 \\
\hline \multirow[t]{2}{*}{$\alpha=0.65$} & $\hat{d}$ & 0.6490 & 0.6511 & 0.6909 & 0.6939 \\
\hline & $H_{0}: \hat{d}=1$ & -1.9543 & -1.9427 & -1.7207 & -1.7044 \\
\hline
\end{tabular}


Table 3 continued

\begin{tabular}{llrrrr}
\hline & & LW & ELW & FELW & FELW dt \\
\hline Washington -199 obs. & $\hat{d}$ & & & & \\
$\alpha=0.575$ & & 0.6389 & 0.5283 & 0.6279 & 0.6457 \\
& $H_{0}: \hat{d}=1$ & -1.6149 & -2.1097 & -1.6642 & -2.3884 \\
$\alpha=0.6$ & $\hat{d}$ & 0.6146 & 0.5386 & 0.6346 & 0.4812 \\
& $H_{0}: \hat{d}=1$ & -1.8481 & -2.2130 & -1.7525 & -2.4880 \\
$\alpha=0.625$ & $\hat{d}$ & 0.6593 & 0.5593 & 0.6394 & 0.5480 \\
& $H_{0}: \hat{d}=1$ & -1.7704 & -2.2899 & -1.8736 & -2.3487 \\
$\alpha=0.65$ & $\hat{d}$ & 0.6272 & 0.5361 & 0.6171 & 0.4961 \\
& $H_{0}: \hat{d}=1$ & -2.0757 & -2.5826 & -2.1319 & -2.8058 \\
\hline
\end{tabular}


Table 4 Long memory test for City' gasoline price time series

\begin{tabular}{|c|c|c|c|c|c|}
\hline & & LW & ELW & FELW & FELW dt \\
\hline \multicolumn{6}{|l|}{ Boston - 199 obs. } \\
\hline \multirow[t]{2}{*}{$\alpha=0.575$} & $\hat{d}$ & 0.3087 & 0.2997 & 0.3560 & 0.2374 \\
\hline & $H_{0}: \hat{d}=1$ & -3.0918 & -3.1319 & -2.8801 & -3.4105 \\
\hline \multirow[t]{2}{*}{$\alpha=0.6$} & $\hat{d}$ & 0.3764 & 0.3365 & 0.4075 & 0.3002 \\
\hline & $H_{0}: \hat{d}=1$ & -2.9907 & -3.1822 & -2.8417 & -3.3563 \\
\hline \multirow[t]{2}{*}{$\alpha=0.625$} & $\hat{d}$ & 0.4140 & 0.3571 & 0.4320 & 0.3352 \\
\hline & $H_{0}: \hat{d}=1$ & -3.0450 & -3.3409 & -2.9513 & -3.4545 \\
\hline \multirow[t]{2}{*}{$\alpha=0.65$} & $\hat{d}$ & 0.4534 & 0.4064 & 0.4736 & 0.3926 \\
\hline & $H_{0}: \hat{d}=1$ & -3.0432 & -3.3048 & -2.9307 & -3.3818 \\
\hline \multicolumn{6}{|l|}{ Chicago - 199 obs. } \\
\hline \multirow[t]{2}{*}{$\alpha=0.575$} & $\hat{d}$ & 0.1502 & 0.1432 & 0.1402 & 0.1209 \\
\hline & $H_{0}: \hat{d}=1$ & -3.8002 & -3.8317 & -3.8453 & -3.9315 \\
\hline \multirow[t]{2}{*}{$\alpha=0.6$} & $\hat{d}$ & 0.1348 & 0.1362 & 0.1368 & 0.1190 \\
\hline & $H_{0}: \hat{d}=1$ & -4.1496 & -4.1429 & -4.1396 & -4.2250 \\
\hline \multirow[t]{2}{*}{$\alpha=0.625$} & $\hat{d}$ & 0.1697 & 0.1766 & 0.1765 & 0.1593 \\
\hline & $H_{0}: \hat{d}=1$ & -4.3143 & -4.2784 & -4.2788 & -4.3685 \\
\hline \multirow[t]{2}{*}{$\alpha=0.65$} & $\hat{d}$ & 0.1985 & 0.2120 & 0.2119 & 0.1959 \\
\hline & $H_{0}: \hat{d}=1$ & -4.4628 & -4.3871 & -4.3879 & -4.4771 \\
\hline \multicolumn{6}{|l|}{ Cleveland - 199 obs. } \\
\hline \multirow[t]{2}{*}{$\alpha=0.575$} & $\hat{d}$ & 0.6361 & 0.5287 & 0.5929 & 0.4886 \\
\hline & $H_{0}: \hat{d}=1$ & -1.6273 & -2.1075 & -1.8206 & -2.2872 \\
\hline \multirow[t]{2}{*}{$\alpha=0.6$} & $\hat{d}$ & 0.5052 & 0.4412 & 0.4946 & 0.3855 \\
\hline & $H_{0}: \hat{d}=1$ & -2.3728 & -2.6797 & -2.4236 & -2.9473 \\
\hline \multirow[t]{2}{*}{$\alpha=0.625$} & $\hat{d}$ & 0.5606 & 0.4811 & 0.5352 & 0.4407 \\
\hline & $H_{0}: \hat{d}=1$ & -2.2831 & -2.6965 & -2.4153 & -2.9063 \\
\hline \multirow[t]{2}{*}{$\alpha=0.65$} & $\hat{d}$ & 0.4779 & 0.4254 & 0.4722 & 0.3771 \\
\hline & $H_{0}: \hat{d}=1$ & -2.9070 & -3.1992 & -2.9388 & -3.4682 \\
\hline \multicolumn{6}{|l|}{ Denver - 199 obs. } \\
\hline \multirow[t]{2}{*}{$\alpha=0.575$} & $\hat{d}$ & 0.1638 & 0.1425 & 0.1628 & -0.1797 \\
\hline & $H_{0}: \hat{d}=1$ & -3.7397 & -3.8351 & -3.7440 & -5.2757 \\
\hline \multirow[t]{2}{*}{$\alpha=0.6$} & $\hat{d}$ & 0.1491 & 0.1409 & 0.1497 & -0.1669 \\
\hline & $H_{0}: \hat{d}=1$ & -4.0808 & -4.1202 & -4.0779 & -5.5964 \\
\hline \multirow[t]{2}{*}{$\alpha=0.625$} & $\hat{d}$ & 0.1871 & 0.1553 & 0.1823 & -0.1018 \\
\hline & $H_{0}: \hat{d}=1$ & -4.2241 & -4.3892 & -4.2489 & -5.7250 \\
\hline \multirow[t]{2}{*}{$\alpha=0.65$} & $\hat{d}$ & 0.2157 & 0.1666 & 0.2085 & -0.0458 \\
\hline & $H_{0}: \hat{d}=1$ & -4.3668 & -4.6401 & -4.4068 & -5.8229 \\
\hline
\end{tabular}


Table 4 continued

\begin{tabular}{|c|c|c|c|c|c|}
\hline & & LW & ELW & FELW & FELW dt \\
\hline \multicolumn{6}{|l|}{ Houston - 199 obs. } \\
\hline \multirow[t]{2}{*}{$\alpha=0.575$} & $\hat{d}$ & 0.6823 & 0.5023 & 0.7074 & 0.7067 \\
\hline & $H_{0}: \hat{d}=1$ & -1.4209 & -2.2260 & -1.3087 & -1.3118 \\
\hline \multirow[t]{2}{*}{$\alpha=0.6$} & $\hat{d}$ & 0.6446 & 0.5778 & 0.6855 & 0.6845 \\
\hline & $H_{0}: \hat{d}=1$ & -1.7047 & -2.0248 & -1.5084 & -1.5133 \\
\hline \multirow[t]{2}{*}{$\alpha=0.625$} & $\hat{d}$ & 0.7247 & 0.6953 & 0.7589 & 0.7296 \\
\hline & $H_{0}: \hat{d}=1$ & -1.4304 & -1.5835 & -1.2530 & 1.4050 \\
\hline \multirow[t]{2}{*}{$\alpha=0.65$} & $\hat{d}$ & 0.6727 & 0.7604 & 0.7337 & 0.6972 \\
\hline & $H_{0}: \hat{d}=1$ & -1.8221 & -1.3338 & -1.4825 & -1.6861 \\
\hline \multirow{3}{*}{$\begin{array}{l}\text { Los Angeles - } 199 \text { obs. } \\
\alpha=0.575\end{array}$} & & & & & \\
\hline & $\hat{d}$ & 0.6423 & 0.6790 & 0.6833 & 0.6404 \\
\hline & $H_{0}: \hat{d}=1$ & -1.5997 & -1.4354 & -1.4163 & -1.6082 \\
\hline \multirow[t]{2}{*}{$\alpha=0.6$} & $\hat{d}$ & 0.6302 & 0.7065 & 0.6794 & 0.6262 \\
\hline & $H_{0}: \hat{d}=1$ & -1.7736 & -1.4078 & -1.5374 & -1.7927 \\
\hline \multirow[t]{2}{*}{$\alpha=0.625$} & $\hat{d}$ & 0.6783 & 0.7144 & 0.7041 & 0.6505 \\
\hline & $H_{0}: \hat{d}=1$ & -1.6714 & -1.4839 & -1.5376 & -1.8160 \\
\hline \multirow[t]{2}{*}{$\alpha=0.65$} & $\hat{d}$ & 0.6535 & 0.7021 & 0.6828 & 0.6344 \\
\hline & $H_{0}: \hat{d}=1$ & -1.9290 & -1.6587 & -1.7660 & -2.0353 \\
\hline \multirow{3}{*}{$\begin{array}{l}\text { Miami - } 199 \text { obs. } \\
\alpha=0.575\end{array}$} & & & & & \\
\hline & $\hat{d}$ & 0.4750 & 0.5961 & 0.5851 & 0.5944 \\
\hline & $H_{0}: \hat{d}=1$ & -2.3478 & -1.8062 & -1.8555 & -1.8138 \\
\hline \multirow[t]{2}{*}{$\alpha=0.6$} & $\hat{d}$ & 0.5369 & 0.6359 & 0.6225 & 0.6238 \\
\hline & $H_{0}: \hat{d}=1$ & -2.2209 & -1.7463 & -1.8103 & -1.8043 \\
\hline \multirow[t]{2}{*}{$\alpha=0.625$} & $\hat{d}$ & 0.5864 & 0.6671 & 0.6535 & 0.6463 \\
\hline & $H_{0}: \hat{d}=1$ & -2.1492 & -1.7296 & -1.8006 & -1.8381 \\
\hline \multirow[t]{2}{*}{$\alpha=0.65$} & $\hat{d}$ & 0.5980 & 0.6481 & 0.6466 & 0.6481 \\
\hline & $H_{0}: \hat{d}=1$ & -2.2381 & -1.9593 & -1.9674 & -1.9591 \\
\hline \multirow{3}{*}{$\begin{array}{l}\text { New York City - } 199 \text { obs. } \\
\alpha=0.575\end{array}$} & & & & & \\
\hline & $\hat{d}$ & 0.3113 & 0.3793 & 0.3969 & 0.2024 \\
\hline & $H_{0}: \hat{d}=1$ & -3.0798 & -2.7760 & -2.6971 & -3.5672 \\
\hline \multirow[t]{2}{*}{$\alpha=0.6$} & $\hat{d}$ & 0.3879 & 0.4323 & 0.4554 & 0.2851 \\
\hline & $H_{0}: \hat{d}=1$ & -2.9357 & -2.7227 & -2.6117 & -3.4287 \\
\hline \multirow[t]{2}{*}{$\alpha=0.625$} & $\hat{d}$ & 0.4458 & 0.4544 & 0.4814 & 0.3305 \\
\hline & $H_{0}: \hat{d}=1$ & -2.8799 & -2.8351 & -2.6947 & -3.4790 \\
\hline \multirow[t]{2}{*}{$\alpha=0.65$} & $\hat{d}$ & 0.5179 & 0.4940 & 0.5214 & 0.3944 \\
\hline & $H_{0}: \hat{d}=1$ & -2.6840 & -2.8170 & -2.6650 & -3.3717 \\
\hline
\end{tabular}


Table 4 continued

\begin{tabular}{llrrrr}
\hline & & LW & ELW & FELW & FELW dt \\
\hline San Francisco - 199 obs. & $\hat{d}$ & & & & \\
$\alpha=0.575$ & $H_{0}: \hat{d}=1$ & -1.2734 & -1.4213 & -1.1076 & -1.5743 \\
$\alpha=0.6$ & $\hat{d}$ & 0.6353 & 0.6705 & 0.6047 & 0.6181 \\
& $H_{0}: \hat{d}=1$ & -1.7489 & -1.5803 & -1.8957 & -1.8316 \\
$\alpha=0.625$ & $\hat{d}$ & 0.6855 & 0.6656 & 0.6394 & 0.6401 \\
& $H_{0}: \hat{d}=1$ & -1.6344 & -1.7375 & -1.8739 & -1.8699 \\
$\alpha=0.65$ & $\hat{d}$ & 0.6945 & 0.6804 & 0.6458 & 0.6429 \\
& $H_{0}: \hat{d}=1$ & -1.7011 & -1.7792 & -1.9721 & -1.9884 \\
\hline Seattle -199 obs. & $\hat{d}$ & & & & \\
$\alpha=0.575$ & $H_{0}: \hat{d}=1$ & -1.6373 & -1.9664 & -1.6394 & -2.4526 \\
& $\hat{d}$ & 0.5659 & 0.5407 & 0.6378 & 0.4401 \\
$\alpha=0.6$ & $H_{0}: \hat{d}=1$ & -2.0818 & -2.2028 & -1.7368 & -2.6850 \\
$\alpha=0.625$ & $\hat{d}$ & 0.6056 & 0.5471 & 0.6302 & 0.4599 \\
& $H_{0}: \hat{d}=1$ & -2.0496 & -2.3533 & -1.9216 & -2.8066 \\
$\alpha=0.65$ & $\hat{d}$ & 0.6075 & 0.5309 & 0.6105 & 0.4502 \\
& $H_{0}: \hat{d}=1$ & -2.1853 & -2.6116 & -2.1686 & -3.0609 \\
\hline
\end{tabular}


Figure 1: EIA PADDs, States and Cities

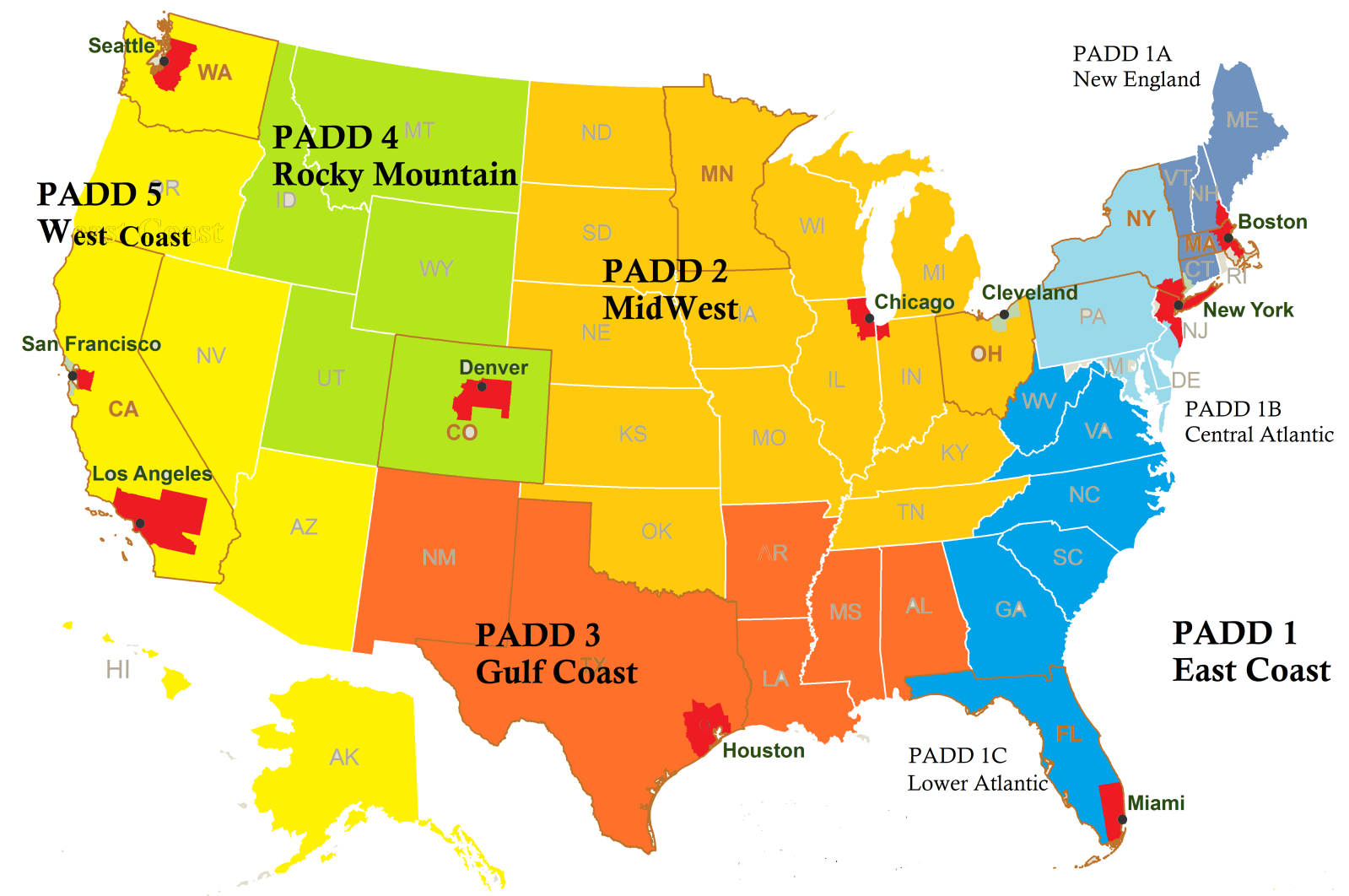


Figure 2: Gasoline prices in PADDs
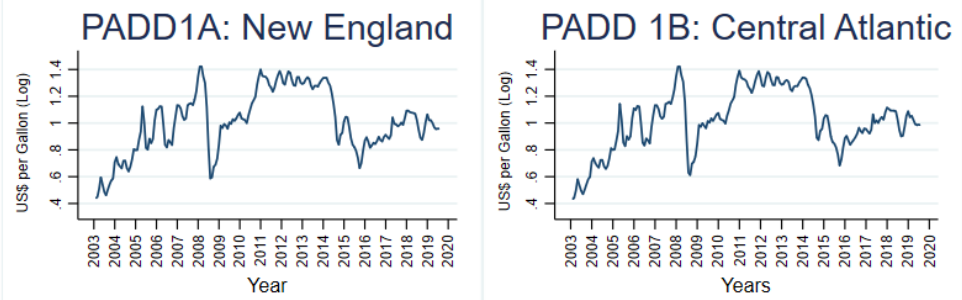

PADD 1C: Lower Atlantic

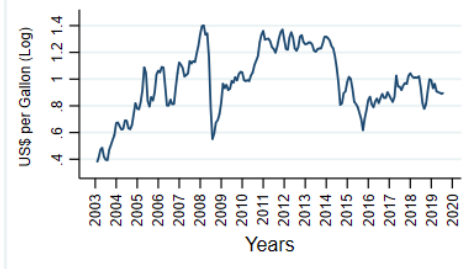

PADD2 Midwest

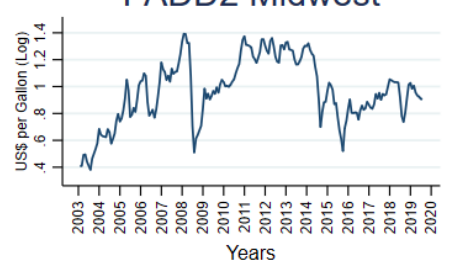

PADD3: Gulf Coast

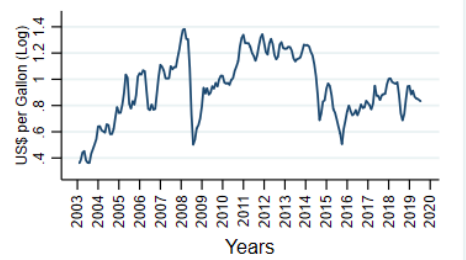

PADD4: Rocky Mountain

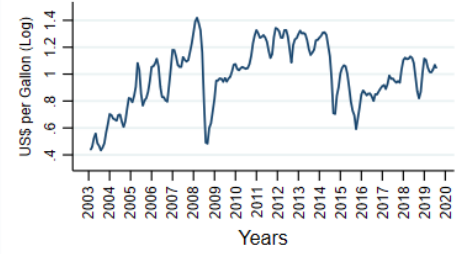

PADD5: West Coast

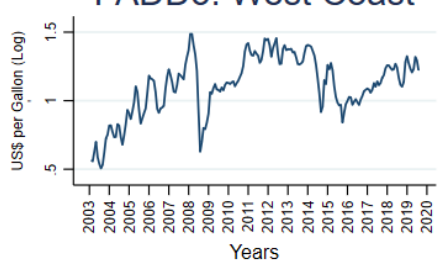


Figure 3: EIA:States Trend
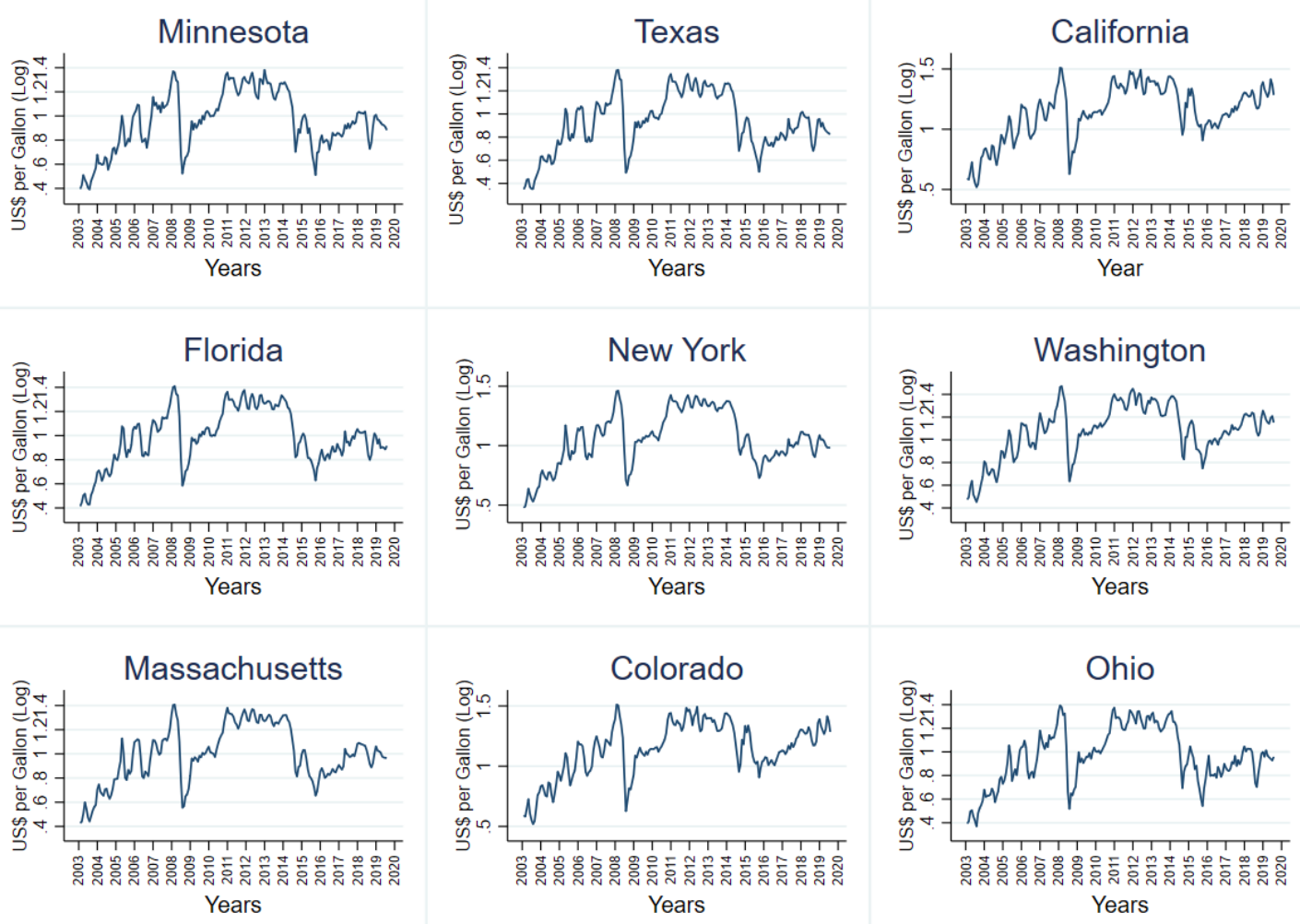
Figure 4: EIA:Cities Trend
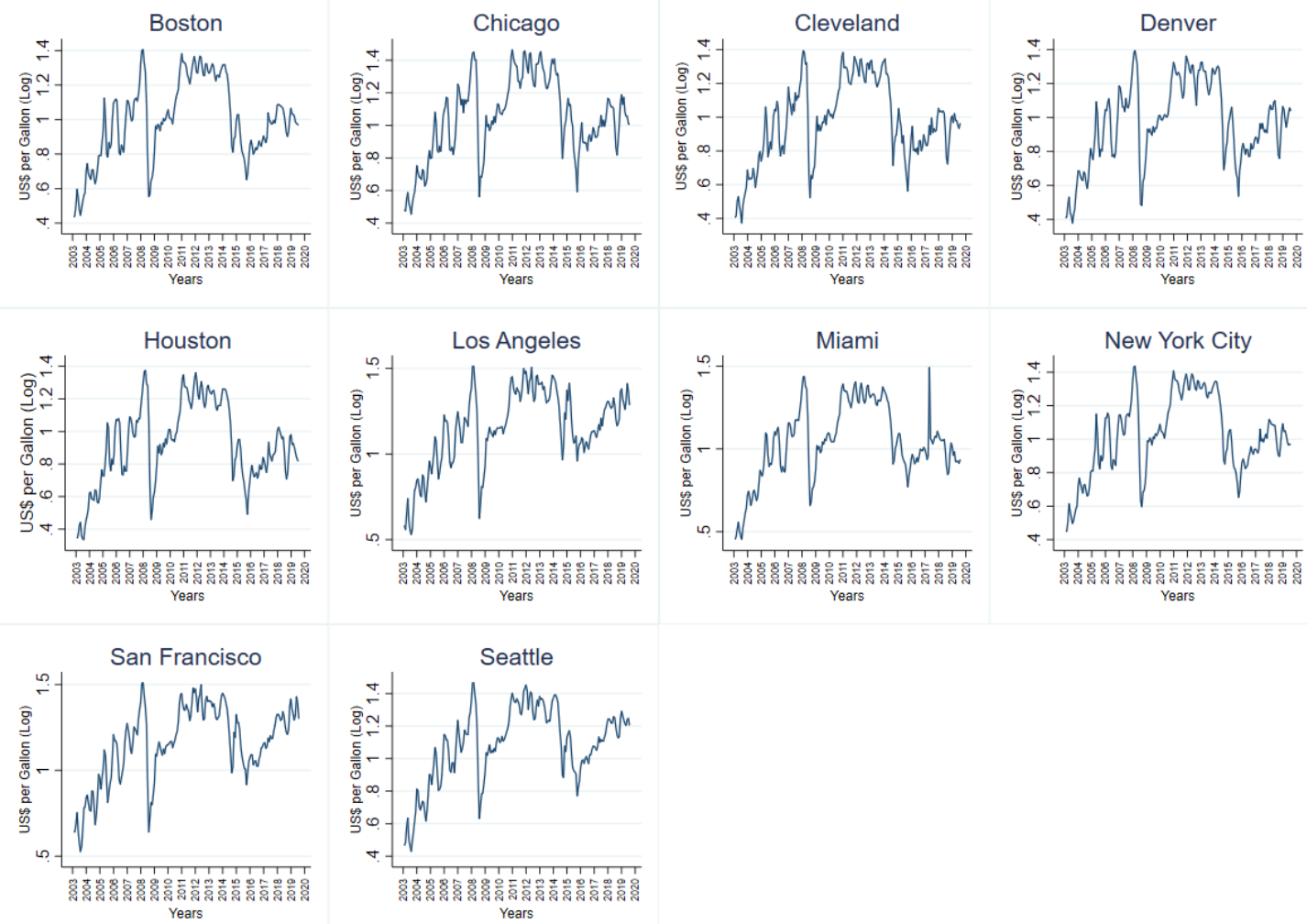
Appendix

\section{A Long Memory Models}

In this subsection we briefly introduce fractionally integrated/long memory models and their estimation. Granger and Joyeux (1980) suggest that a stationary time series $\left\{y_{t}\right\}$ has long memory if there is a non zero $d \in(-0.5,0.5)$ such that its spectral density obeys a power law $f(\lambda) \sim k \lambda^{-2 d}$ as $\lambda \rightarrow 0^{+}$. Clearly, as $\lambda \rightarrow 0, f(\lambda) \rightarrow \infty$, if $d>0$ or $f(\lambda) \rightarrow 0$, if $d<0$. In the case where $d=0,\left\{y_{t}\right\}$ will have short memory and $(0<f(0)<\infty)$ such as in the case of all the stationary and invertible ARMA processes. Moreover, HoskNG (1981) identified the relationship between long memory models and fractional differencing, proposing a class of models denominated fractional ARIMA, where the degree of differencing can be any real number. The simplest of these is the fractionally integrated noise or $\operatorname{ARIMA}(0, d, 0)$ defined for $d>-1$, that is:

$$
\Delta^{d} y_{t}=\epsilon_{t} ; \quad \epsilon \sim i i d\left(0, \sigma^{2}\right), \text { and }, \Delta^{d}=(1-L)^{d} .
$$

To obtain an $A R I M A(0, d, 0)$ for $d$ that lies outside the range $(-0.5,0.5)$, it is sufficient to start with an $A R I M A(0, \bar{d}, 0)$, with $\bar{d} \in(-.05,0.5)$, such that $d-\bar{d}$ is an integer. If $d>0.5$, we need to integrate $d-\bar{d}$ times, if $d<0.5$, we difference $d-\bar{d}$ times. The result will be an $A R I M A(0, d, 0)$ which however will not be stationary if $d \geq 0.5$.

The more general fractional ARIMA (p,d,q)can be written as:

$$
\phi(L) \Delta^{d} y_{t}=\theta(L) \epsilon_{t},
$$

where $\epsilon_{t}$ is as before a zero mean white noise process, $d \in(-0.5,0.5)$, and $\phi(L)$ and $\theta(L)$ are polynomial in the lag operator or order $p$ and $q$ respectively. The $\operatorname{ARIMA}(\mathrm{p}, \mathrm{d}, \mathrm{q})$ can also be written as

$$
\phi(L) y_{t}=\theta(L)\left(\Delta^{-d} \epsilon_{t}\right),
$$

showing that the $\operatorname{ARIMA}(\mathrm{p}, \mathrm{d}, \mathrm{q})$ can be thought of as an $\operatorname{ARMA}(\mathrm{p}, \mathrm{q})$ driven by a fractionally integrated $\operatorname{ARIMA}(0, \mathrm{~d}, 0)$ noise, $\Delta^{-d} \epsilon_{t}$. The spectral density for the $\operatorname{ARIMA}(\mathrm{p}, \mathrm{d}, \mathrm{q})$ is:

$$
f(\lambda)=\frac{\sigma_{\epsilon}^{2}}{2 \pi}\left|\theta\left(e^{-i \lambda}\right) / \phi\left(e^{-i \lambda}\right)\right|^{2}\left|1-e^{-i \lambda}\right|^{-2 d}
$$

and as $\lambda \rightarrow 0^{+}$

$$
f(\lambda)=\frac{\sigma_{\epsilon}^{2}}{2 \pi}|\theta(1) / \phi(1)|^{2}|\lambda|^{-2 d} .
$$

Again, if $d \neq 0$, then $y_{t}$ is a long memory process and it can be shown that its autocovariances obey the power law $c_{r} \sim k r^{2 d-1}$ as $r \rightarrow \infty$. 
Alternatively we could write the spectral density of the fractional $\operatorname{ARIMA}(\mathrm{p}, \mathrm{d}, \mathrm{q})$ as:

$$
f(\lambda)=\frac{\sigma^{2}}{2 \pi}\left|1-e^{-i \lambda}\right|^{-2 d} g(\lambda)
$$

where $g(\lambda)$ is the spectral density of an $\operatorname{ARMA}(\mathrm{p}, \mathrm{q}) .^{2}$

The ARMA parameters as well as $d$ are unknown and must be estimated. Assuming that $\mathrm{p}$ and $\mathrm{q}$ are known and that $\left\{\epsilon_{t}\right\}$ are Gaussian, we can use maximum likelihood estimation (MLE) to estimate the ARMA parameters as well as $d$. However, the MLE of this type of model requires $O\left(n^{3}\right)$ operations to evaluate the likelihood function. To avoid such intense computation, Fox and Taqqu (1986) suggest using the Whittle approximation to the likelihood function, that is:

$$
-2 \log l(\Theta) \approx \sum_{j=1}^{n / 2}\left[\log f_{\Theta}\left(\lambda_{j}\right)+I_{j} / f_{\Theta}\left(\lambda_{j}\right)\right]
$$

where $\Theta$ is the vector of ARMA parameters plus $d$, and $f_{\Theta}(\lambda)$ is the spectral density of the $\operatorname{ARIMA}(\mathrm{p}, \mathrm{d}, \mathrm{q})$ process. The Whittle estimator $(\mathrm{WE})$ is obtained by minimisation with respect to $\Theta$. Fox and Taqqu (1986) show that the Whittle estimator of $\Theta$, say $\hat{\Theta}_{W}$, is asymptotically equivalent to the exact MLE assuming that $d>0$, the model is correct, and the order of $\mathrm{p}$ and $\mathrm{q}$ is known.

However, $\mathrm{p}$ and $\mathrm{q}$ are unknown, and as a result both the ML and $\mathrm{W}$ estimators of $d$ will be asymptotically biased. The same problem will arise if $g(\lambda)$ is not ARMA but it is assumed that it is.

To overcome the problem, Robinson (1995) proposed a semi-parametric Gaussian estimator for $d$ known as the Local Whittle (LW) estimator, which is developed under the assumption that $y_{t}$ is stationary and its spectral density behaves like $G \lambda^{-2 d}$ as $\lambda \rightarrow 0^{+}$. The frequency domain Gaussian likelihood in the vicinity of the origin is:

$$
Q_{m}(G, d)=m^{-1} \sum_{j=1}^{m}\left[\log \left(G \lambda_{j}^{-2 d}\right)+\frac{\lambda_{j}^{2 d}}{G} I\left(\lambda_{j}\right)\right],
$$

where as before $m<n$ is an integer controlling the number of frequencies included in the local likelihood. Estimates of $G$ and $d$ are then obtained through the minimisation of $Q_{m}(G, d)$ such that:

$$
(\hat{G}, \hat{d})=\arg \min _{G \in(0, \infty), d \in\left[\Delta_{1}, \Delta_{2}\right]} \quad Q_{m}(G, d),
$$

\footnotetext{
${ }^{2}$ The fractional $\operatorname{ARIMA}(\mathrm{p}, \mathrm{d}, \mathrm{q})$ is particularly convenient as it can be used to describe both the long and the short term behaviour of the $y_{t}$. In fact $d$ determines the long term correlations and the behaviour of the spectral density near zero frequency and the AR and MA parameters describe the short term correlations and shape the spectral density for frequencies not near zero, independently from $d$.
} 
with $\Delta_{1}$ and $\Delta_{2}$ are numbers such that $-\infty<\Delta_{1}<\Delta_{2}<1 / 2$. Concentrating the likelihood with respect to $G$, it is found that $\hat{d}$ satisfies:

$$
\arg \min _{d \in\left[\Delta_{1}, \Delta_{2}\right]} \quad \log \hat{G}(d)-2 d \frac{1}{m} \sum_{j=1}^{m} \log \lambda_{j}, \quad \hat{G}(d)=m^{-1} \sum_{j=1}^{m} \lambda_{j}^{2 d} I\left(\lambda_{j}\right) .
$$

Under appropriate assumptions and conditions, and for $d_{0} \in(-1 / 2,1 / 2)$, Robinson(1995) and Shimotsu and Phillips (2006) show that $\sqrt{m}\left(\hat{d}-d_{0}\right) \rightarrow N(0,1 / 4)$.

Phillips and Shimostu (2004), among others, show that when $d>1 / 2$ the LW estimator exhibits non standard behaviour. Although it is consistent for $d \in(1 / 2,1]$ and asymtotically normal for $d \in(1 / 2,3 / 4)$, the LW has non normal asymptotic distribution for $d \in[3 / 4,1]$, and $d>1$, but also converges to 1 in probability and is inconsistent.

The solution to the problem is provided by Shimotsu and Phillips $(2004,2006)$ who developed the Exact Local Whittle (ELW) estimator and its variants, whose asymptotics are based on the exact frequency domain (or its estimate which will give rise to FELW estimator) of the data generating process which is obtained from the minimisation of the objective function:

$$
Q_{m}^{*}(G, d)=m^{-1} \sum_{j=1}^{m}\left[\log \left(G \lambda_{j}^{-2 d}\right)+\frac{\lambda_{j}^{2 d}}{G} I_{(1-L)^{d} y}\left(\lambda_{j}\right)\right] .
$$

The ELW is computationally more demanding than LW but is shown to be consistent and asymptotically normally distributed for any value of $d$ and therefore is valid under a wider range of cases.

Shimotsu and Phillips (2006) discuss the importance of the choice of $m$, explaining that as in the case of LW and ELW estimation, $m$ has to grow fast for $\hat{d}$ to be consistent, but also that a too large value of $m$ may induce a bias to the estimator from the short run dynamics. A rule of thumb suggests that within $m=n^{\alpha}$, we should choose a value of $\alpha$ around 0.6 (see Shimotsu and Phillips 2006). As we use LW, ELW and FELW to estimate $\hat{d}$ and perform the test $H_{0}: \hat{d}=1$ vs $H_{A}: \hat{d}<1$ for all our series, we derive the exact distribution of the LW, ELW and FELW estimators for $n=200$ and different values of $\alpha$ in the interval $[0.575,0.65]$ as displayed in Table $1 \mathrm{~A}$ in Appendix. Notice that we shall only be concerned with the hypothesis that $\hat{d}=1$ (the series tested has a unit root) against the one sided alternative that $\hat{d}<1$ (the series has long memory but is mean reverting and possibly covariance stationary). That implies that the relevant $90 \%$ and $95 \%$ critical values are the ones corresponding to the 0.1 and 0.05 quantiles respectively for the different values of $\alpha$. 
Table 1A Quantiles of: $H_{0}: \hat{d}=1, \mathrm{n}=200, \alpha \in\{0.575 ; 0.6 ; 0.625 ; 0.65\}$

\begin{tabular}{|c|c|c|c|c|}
\hline Quantile & LW & ELW & FELW & FELW dt \\
\hline \multicolumn{5}{|l|}{$\alpha=0.575$} \\
\hline 0.025 & -1.3675 & -1.4633 & -1.3909 & -1.6551 \\
\hline 0.050 & -1.1191 & -1.2203 & -1.2013 & -1.3535 \\
\hline 0.100 & -0.8713 & -0.9189 & -0.9233 & -0.9553 \\
\hline 0.250 & -0.4624 & -0.4650 & -0.4632 & -0.5053 \\
\hline 0.500 & -0.0649 & -0.0251 & -0.0239 & -0.0405 \\
\hline Mean & -0.0942 & -0.0530 & -0.0479 & -0.0811 \\
\hline St. Dev. & 0.6014 & 0.6726 & 0.6520 & 0.6979 \\
\hline \multicolumn{5}{|l|}{$\alpha=0.6$} \\
\hline$\overline{0.025}$ & -1.3306 & -1.3962 & -1.3474 & -1.6071 \\
\hline 0.050 & -1.1066 & -1.1415 & -1.1397 & -1.2028 \\
\hline 0.100 & -0.8452 & -0.8676 & -0.8633 & -0.9085 \\
\hline 0.250 & -0.4487 & -0.4446 & -0.4426 & -0.4669 \\
\hline 0.500 & -0.0592 & -0.0016 & -0.0040 & -0.0209 \\
\hline Mean & -0.0875 & -0.0295 & -0.0253 & -0.0530 \\
\hline St. Dev. & 0.5855 & 0.6533 & 0.6385 & 0.6780 \\
\hline \multicolumn{5}{|l|}{$\alpha=0.625$} \\
\hline 0.025 & -1.3427 & -1.3672 & -1.3577 & -1.5217 \\
\hline 0.050 & -1.0949 & -1.1116 & -1.1165 & -1.1533 \\
\hline 0.100 & -0.8346 & -0.8380 & -0.8409 & -0.8917 \\
\hline 0.250 & -0.4579 & -0.4312 & -0.4310 & -0.4598 \\
\hline 0.500 & -0.0752 & 0.0034 & 0.0054 & -0.0084 \\
\hline Mean & -0.0989 & -0.0166 & -0.0143 & -0.0376 \\
\hline St. Dev. & 0.5815 & 0.6535 & 0.6445 & 0.6753 \\
\hline \multicolumn{5}{|l|}{$\alpha=0.65$} \\
\hline 0.025 & -1.2798 & -1.3083 & -1.3175 & -1.3563 \\
\hline 0.050 & -1.0617 & -1.0792 & -1.0726 & -1.1109 \\
\hline 0.100 & -0.8415 & -0.8192 & -0.8185 & -0.8532 \\
\hline 0.250 & -0.4644 & -0.4034 & -0.4031 & -0.4254 \\
\hline 0.500 & -0.0987 & 0.0106 & 0.0127 & 0.0048 \\
\hline Mean & -0.1188 & -0.0094 & -0.0078 & -0.0250 \\
\hline St. Dev. & 0.5564 & 0.6299 & 0.6235 & 0.6441 \\
\hline
\end{tabular}

